\title{
Pecan plantation age influences the structures, ecological networks and functions of soil microbial communities
}

\author{
Junping Liu ${ }^{1}$, Yujie Tang ${ }^{1}$, Jiashu Bao ${ }^{1}$, Hankun Wang ${ }^{1}$, Fangren Peng ${ }^{1}$, Mengyun Chen ${ }^{1}$, \\ and Pengpeng Tan ${ }^{1}$ \\ ${ }^{1}$ Nanjing Forestry University
}

January 26, 2022

\begin{abstract}
Understanding the changes in microbial communities with increasing plantation age will benefit the maintenance of forest health and productivity and the sustainable development of forest ecosystems. Based on MiSeq sequencing, we carried out the first study on the effects of stand age on microbial communities in rhizosphere and bulk soils of pecan plantation. The results suggested that soil bacterial alpha diversity increased significantly with plantation age, while fungal alpha diversity was less influenced. Bacterial and fungal biomarkers differed by age group. The fungal community composition was significantly altered by plantation age as reflected by the increase and decrease in the relative abundances of Basidiomycetes and Ascomycota, respectively. The $\mathrm{pH}$ and AP and TK contents drove microbial community structure and composition. The bacterial network was more complex than the fungal network, and simpler and more stable microbial network structures occurred in the rhizosphere soil than in the bulk soil. With increasing plantation age, the risk from plant pathogenic fungi increased, and the functional profile of the microbial community shifted from the nitrogen cycle to carbon utilization.
\end{abstract}

\section{Hosted file}

Title page.doc available at https://authorea.com/users/457266/articles/554092-pecanplantation-age-influences-the-structures-ecological-networks-and-functions-of-soilmicrobial-communities

\section{Hosted file}

manuscript.doc available at https://authorea.com/users/457266/articles/554092-pecanplantation-age-influences-the-structures-ecological-networks-and-functions-of-soilmicrobial-communities 

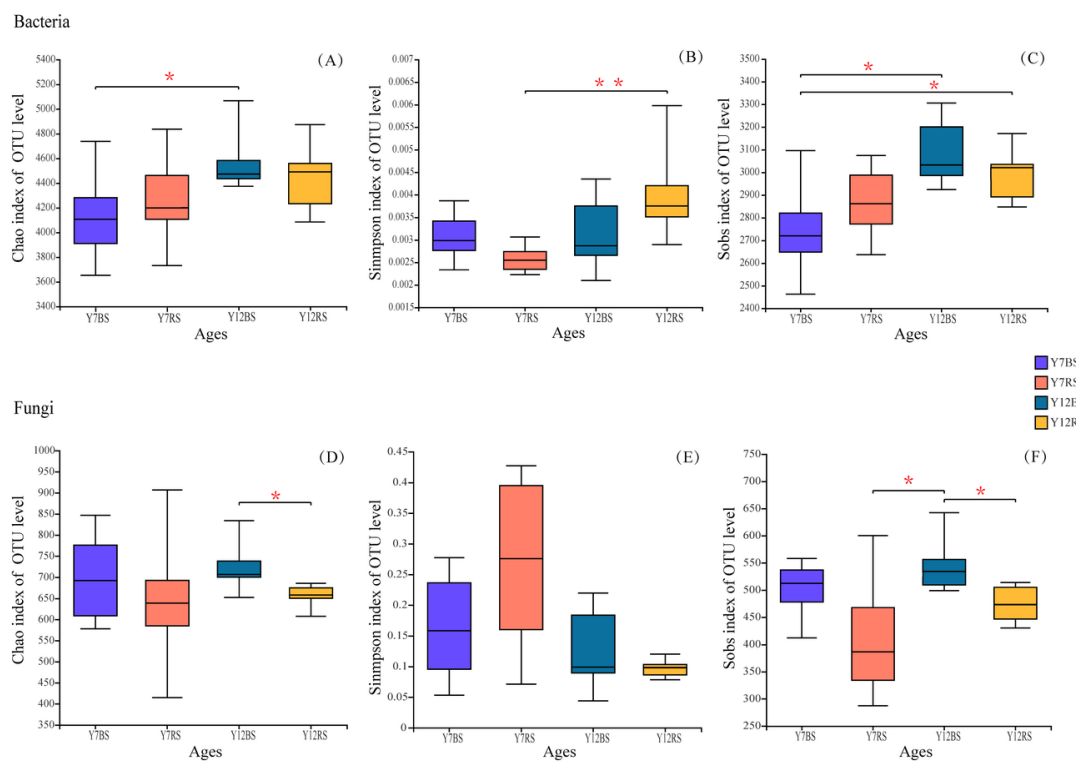

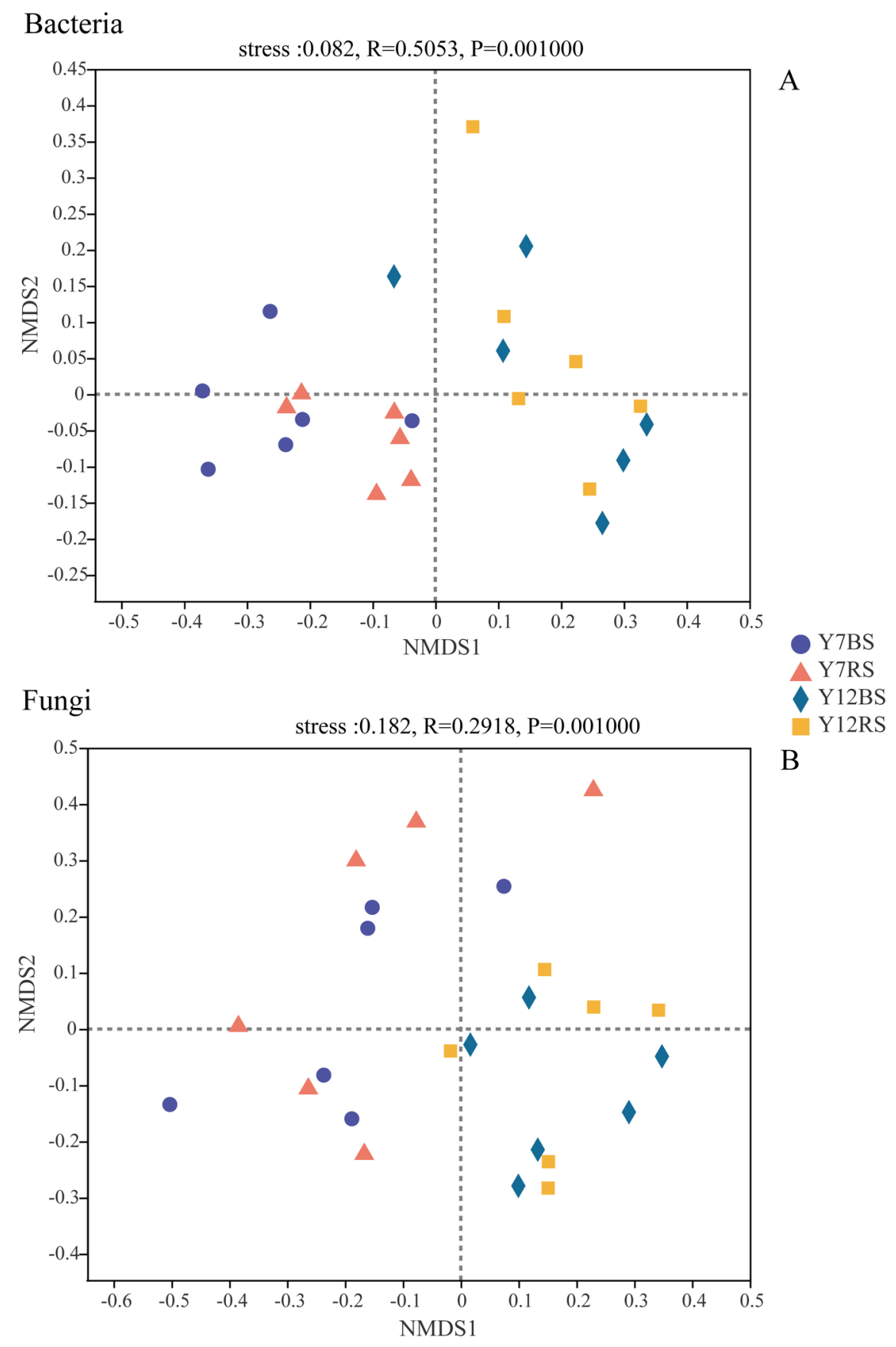

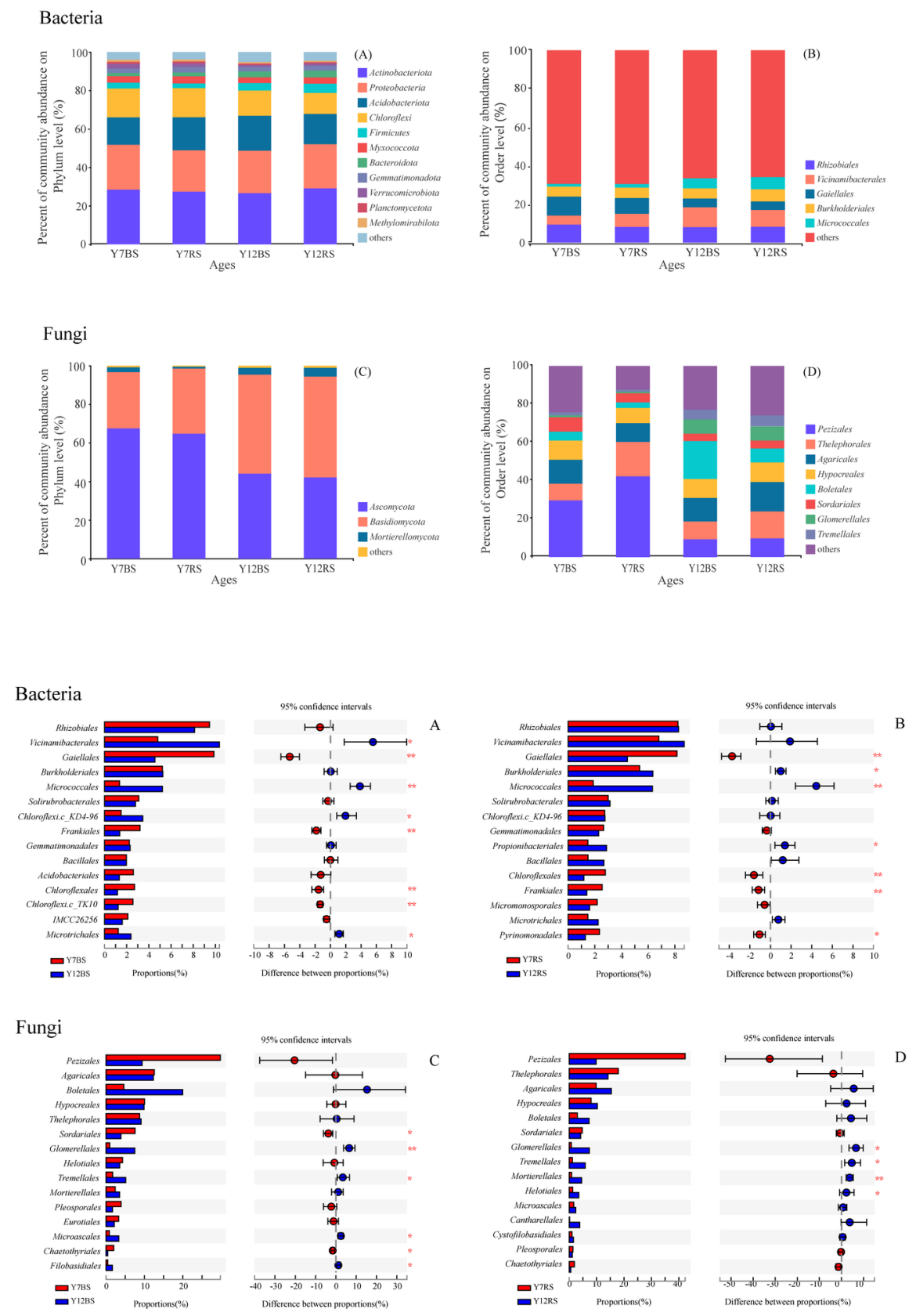


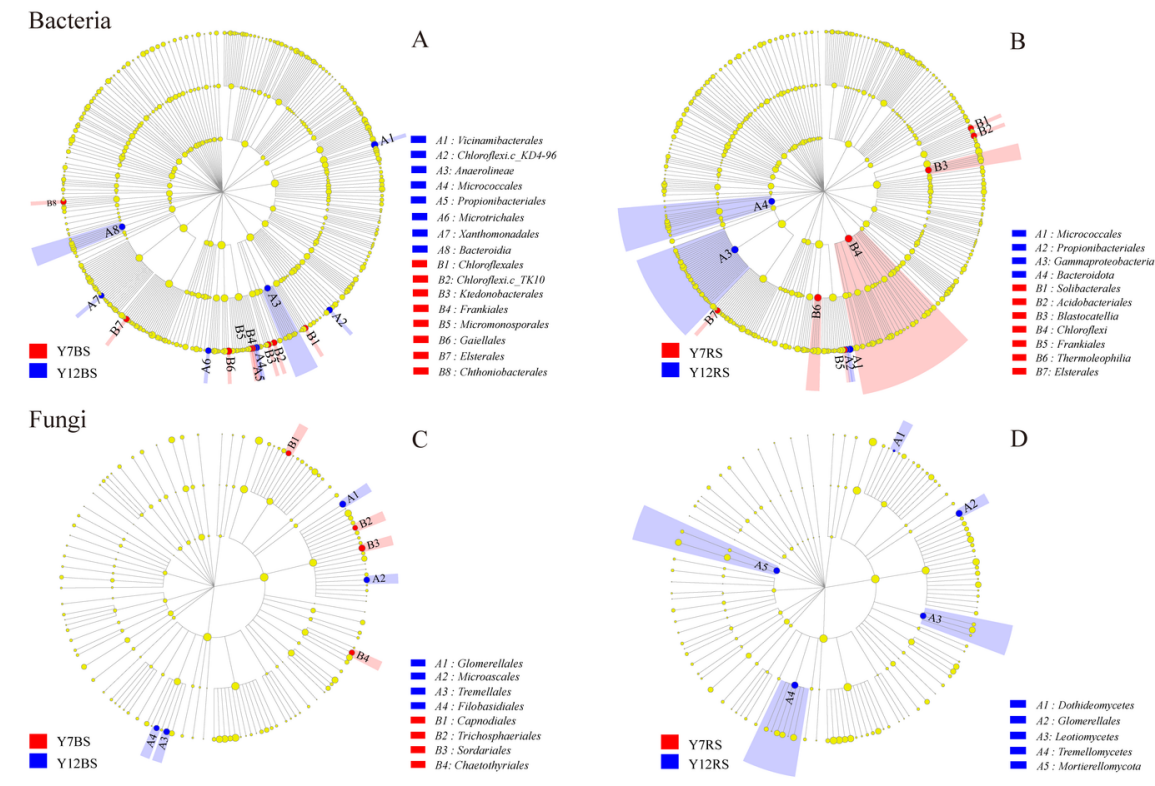




\section{Bacteria}

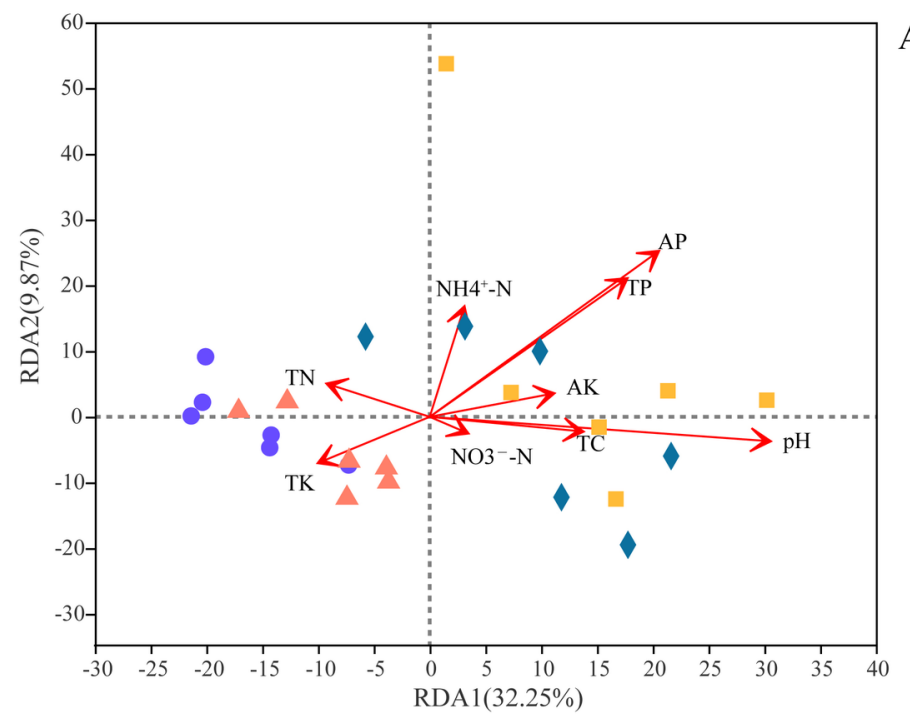

Fungi

A

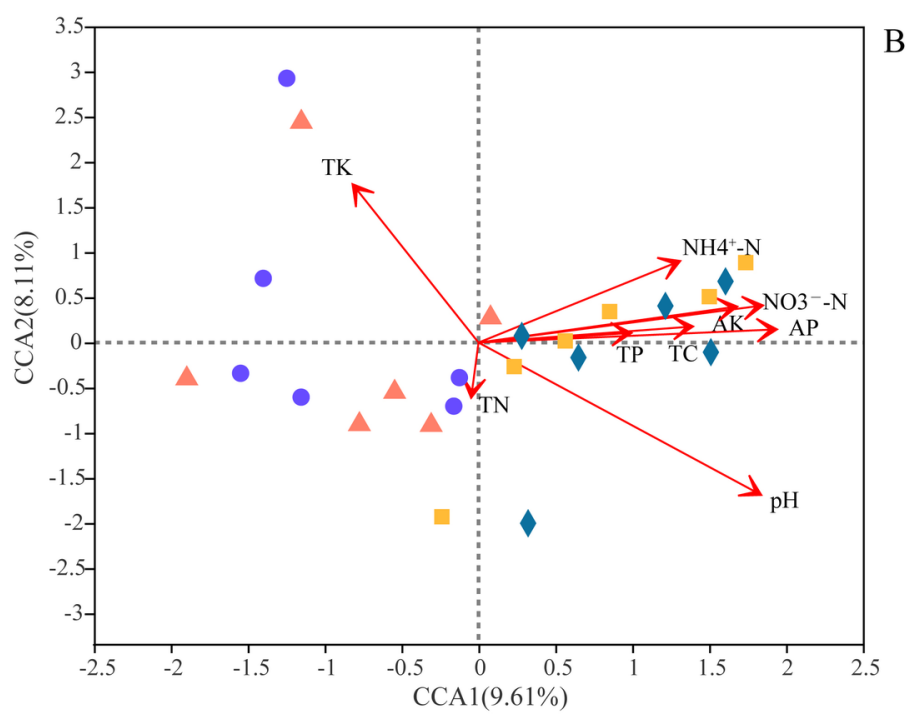



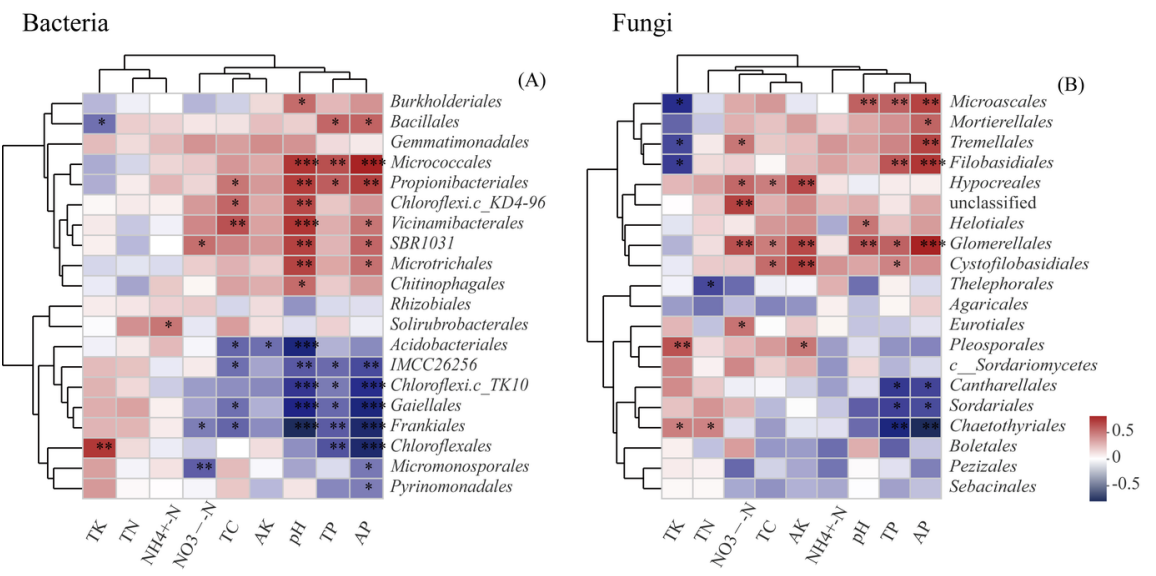

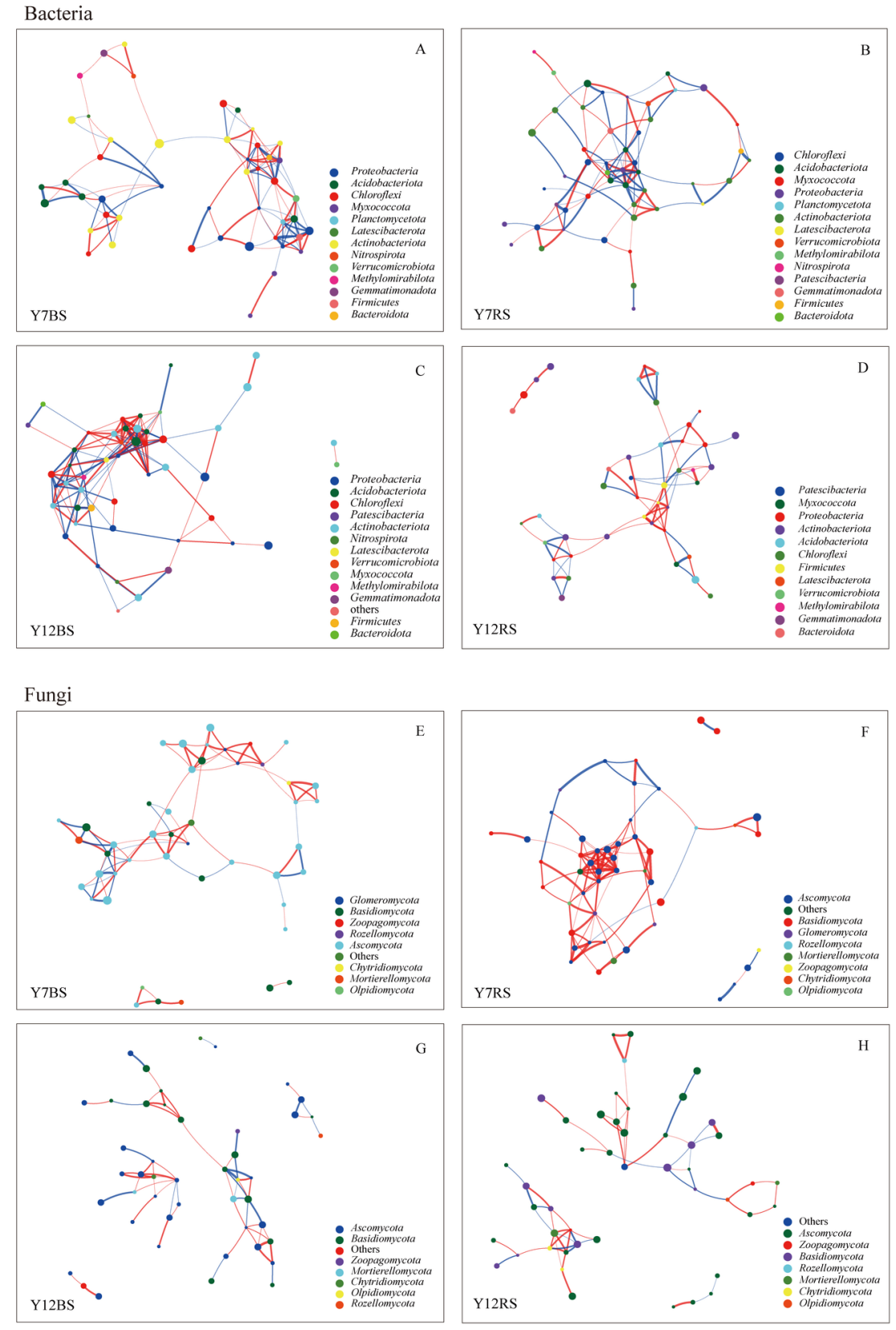

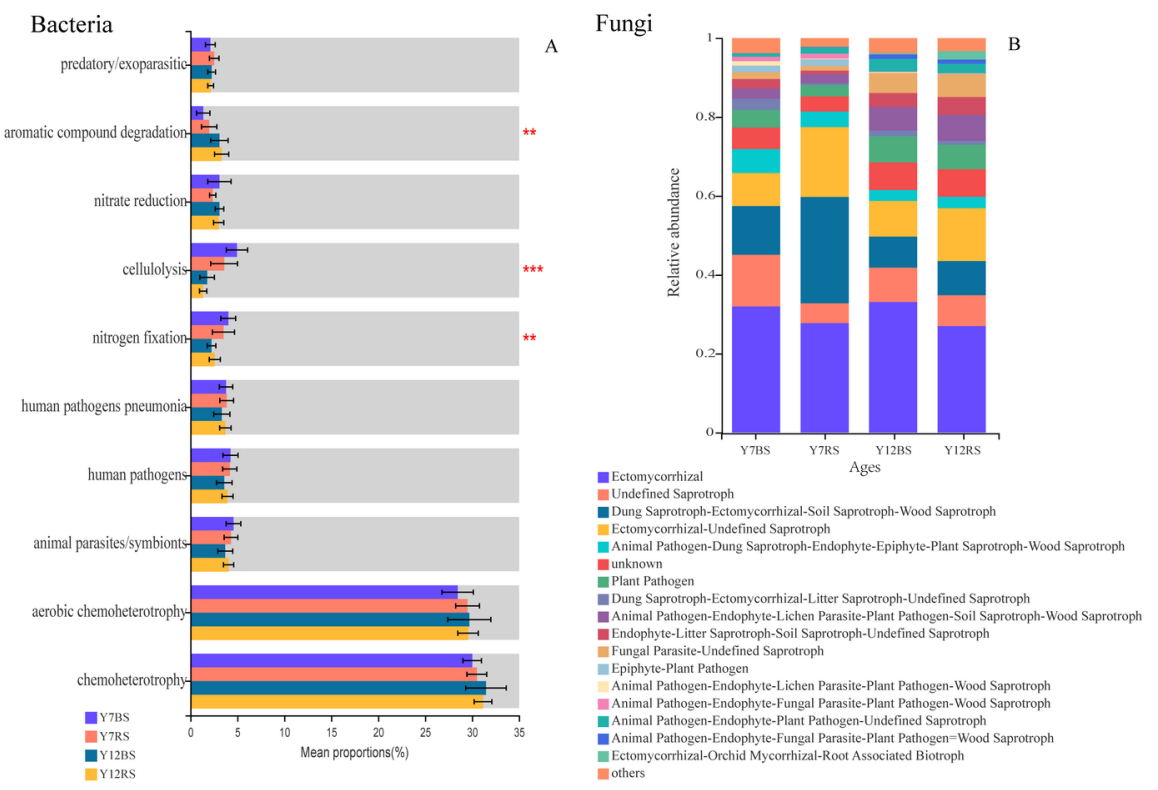